\title{
A pilot study of a novel pulsatile flow generator using large collapsible bladder
}

\author{
Ponangi Udaya Prashant ${ }^{1}$, Nagaraj Balasubramanya ${ }^{2}$ \\ ${ }^{1}$ Institute G-5, Sneha Sindhu Apartments, Kavalabyrasandra, Bangalore; \\ ${ }^{2}$ Department of Civil Engineering, M.S. Ramaiah Engineering College, Bangalore, India. \\ Email: udayaprashant p@yahoo.co.in; jhrumbaa@gmail.com
}

Received 30 April 2010; revised 21 May 2010; accepted 22 May 2010.

\begin{abstract}
Background: There are different experimental models avialable for generating pulsatile flow in laboratory and study their heamodynamic effects on blood vessels. We aim to produce a novel pulsatile flow generator utilizing a large collapsible rubber bladder and the phenomenon of fluid structure interactions occurring in a specially designed flexible tube arrangement. Mehtods: Water enters from a reservoir above into a large collapsible bladder made of rubber which opens into ' $U$ ' shaped tube made of flexible material and held by non rigid structures. As liquid starts flowing the distal end of collapsible bladder collapses under the negative atmospheric pressure generated inside closing the mouth of ' $U$ ' shaped tube and produces pulsatile flow. Resuts: The frequency of pulsations, pressure fluctuations and velocity profile resemble that of in vivo blood flow. As the flow entering into collapsible bladder increases the frequency of pulsatile flow decreases and also when height of the collapsible bladder from the ground was changed. The whole cycle of alternate collapse/expansion of collapsible bladder with generation of pulsatile flow continue indefinitely as long as there is enough water in reservoir and vertical gradient to sustain the flow. Conclusions: The pulsatile flow so produced has many of the characteristics of physiological blood flow and can be used to study mechanisms of various cardiovascular diseases in laboratory.
\end{abstract}

Keywords: Collapsible Tubes; Buckling; Pulsatile Flow Generator; Unsteady Flow; Fluid Structure Interactions

\section{INTRODUCTION}

Cardiovascular diseases are major causes of death throughout the world, yet the mechanisms of these diseases, especially atherosclerosis is poorly understood. The most important aspect of the development and progression of cardiovascular diseases is the role of pulsatile flow in hemodynamics of cardiovascular diseases like atherosclerosis [1,2]. Pulsatile flow induces complex shear stress on walls of vessels and is basis for many atherosclerotic diseases like aneurysms and stenotic lesions [3]. A number of attempts have previously been made to simulate pulsatile human arterial flow [4-7].

Hopmann and Liu described a pump that uses an elastic chamber squeezed by a cam, with pressure-actuated check valves [4]. The use of a gear pump controlled by a closed-loop servosystem was reported by Issartier et al. $[4,7]$. Kiyose et al. have described a mechanical piston pump system for simulating peripheral arterial flow [4]. Petersen described a system using two gear pumps, one to generate forward flow and the other to generate reverse flow [5]. A microcomputer regulated a pneumatic control valve so that the total flow at any instant could be controlled. Errikson et al. used a microcomputer controls a motor which in turn drives a piston pump to generate the flow [6]. However, the system appears to lack the flexibility to generate different waveforms.

Many of the existing pulsatile flow generators are complicated, consume significant power and require computers to function [4-7]. They are also expensive and none of them are based on principle of flow limitation occurring in collapsible tubes. Many interesting phenomena are observed like flow limitation and the propensity to develop large amplitude self-excited oscillations during study of flows in collapsible tubes [8].

Flow induce collapse is very common in many physiological situations like regulation of blood vessel caliber, generation of murmurs, snoring sounds, wheezing in airways, micturation etc [9]. The collapsible tubes buckles and collapses at the distal most point of tube as the internal pressure is least between entry and exit end due to viscous pressure drop [10]. Buckled vessels are very flexible and even small changes in fluid pressure can induce large changes of their cross-sectional area [11]. 
Many of the physiologically observed phenomena described above can be reproduced in laboratory experiments using the 'Starling Resistor', shown below [9] (Figure 1). Inside a pressure chamber, a thin-walled elastic tube (typically made of latex rubber) is mounted on two rigid tubes. Fluid (typically air or water) is driven through the tube, either by applying a controlled pressure drop p-entry and p-exit, between the ends of the rigid tubes or by controlling the flow rate $Q$. At sufficiently large Reynolds numbers, the system buckles axisymmetrically and readily produces self-excited oscillations $[9,11]$.

The present experiment may be considered as extreme modification of this basic "Starling Resistor". There are certain practical applications described for pulsatile flow produced by rapid flutter of collapsed tube. Microfiltration performance of Bentonite suspension was greatly enhanced when a pulsatile flow generated from rapid flutter of collapsible tube was used [20]. But the pulsatile flow produced by Waxing et al. was different from the present experimental setup both in mechanism and the pulsatile waveform generated [20].

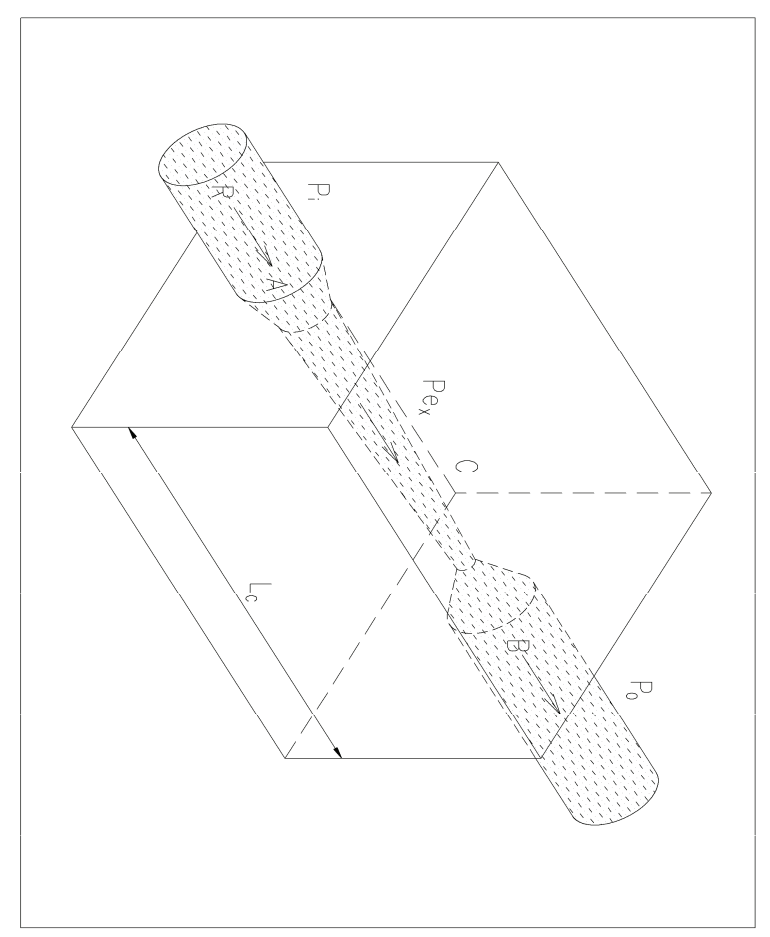

Figure 1. The classic "Starling Resistor". The figure shows how classical Starling Resistor works. The liquid enters the collapsible tube at A with velocity $V$ which is enclosed in a pressurized chamber $\left(\mathrm{p}_{\text {ext }}\right)$ and travels distance $\mathrm{L}$ and starts buckling at $\mathrm{B}$. The diameters of entry and exit pipes are same as that of collapsible tube diameter $\mathrm{R}_{0}$ and all the pipes are aligned in one straight line.
The cyclical opening and collapse of a large rubber bladder used here produces large amplitude low frequency pulsatile flow from continuously flowing liquid unlike previous experiments by a very unique arrangement. The flow very much resembles that occurring inside cardiovascular system of living organisms having characteristics of sinusoidal rise and fall with sharp spike in between during collapse of bladder.

\section{METHODS}

The experimental model can be demonstrated by constructing a simple device using commonly available materials (Figures 2 and 3 ). To a source water that has very negligible head is connected to collapsing rubber bladder. This rubber bladder is highly elastic and the lower end is connected to flexible thin garden hosepipe made of synthetic rubber or PVC. This flexible rubber tube hangs freely after taking initial ' $U$ ' shaped curve. The distal end is open to atmosphere and all the connections are airtight. If the vertical height from the tap to balloon is less than from ground to the balloon $\left(\mathrm{h}_{1}>\mathrm{h}_{\mathrm{o}}\right)$ and during certain range of flow rates it exhibits an interesting phe-

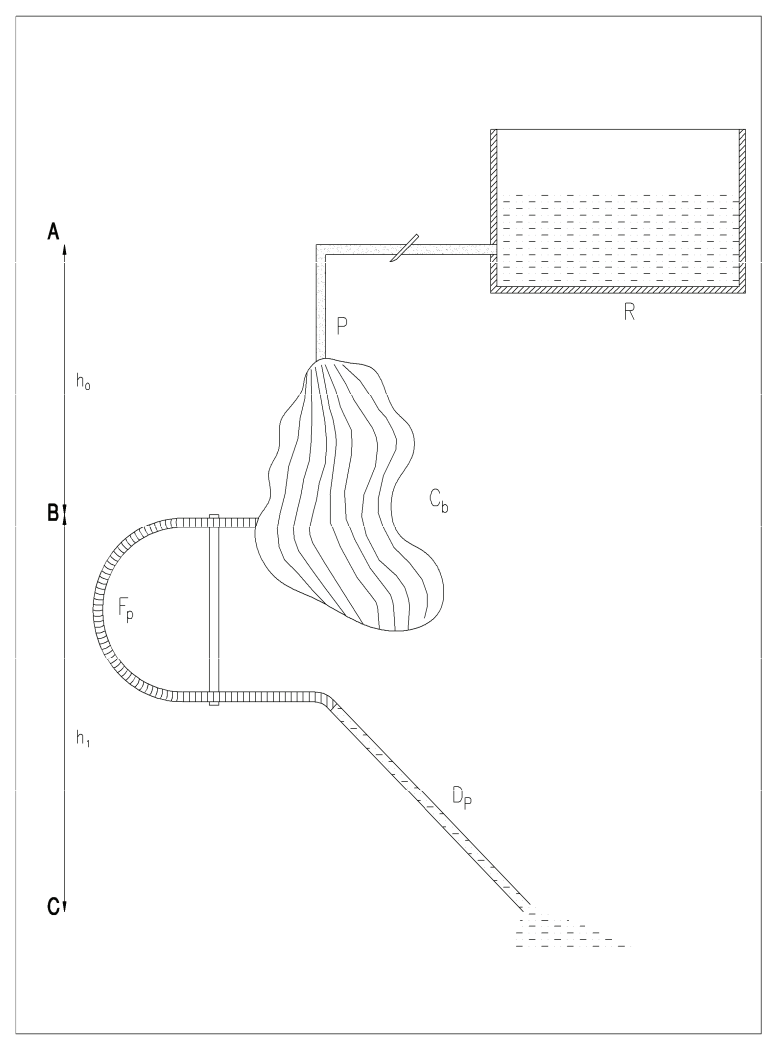

Figure 2. Simple sketch of the novel pulsatile flow generator. $\mathrm{R}$ is reservoir; $\mathrm{P}$ are connecting pipes from reservoir to collapsing bladder $\mathrm{C}_{\mathrm{b}}$. The collapsible bladder is connected to ' $\mathrm{U}$ ' shaped flexible tube $F_{p}$ which is in turn connected to long rigid distal pipe $D_{p}$. 


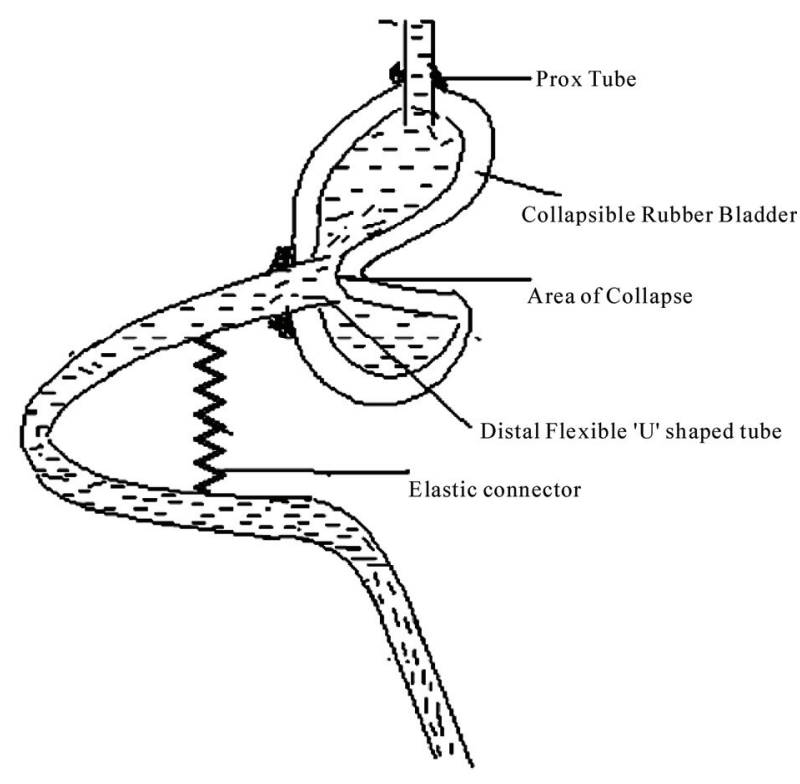

Figure 3. Schematic diagram showing distal flexible ' $U$ ' shaped tube and its attachements.

nomenon of alternate collapse (buckling) and opening, along with generation of pulsatile flow of water. The flow of water or any liquid entering into the collapsible bladder is regulated by a valve and the flow rate can be measured by flow meter attached to it. Pressures are recorded at two points, one at the entry at the collapsible bladder and other at the end of ' $U$ ' tube with help of Phlips portable MP20 monitor and electronic pressure transducer system. Average velocity of flow was calculated by dividing flow rate with area of connecting pipe to collapsible bladder.

Simultaneous pressure was recorded at the proximal and distal end of balloon. The pressure at the entry of the collapsing bladder remains fairly constant at a -ve pressure of -6 to $-12 \mathrm{~cm}$ of water with slight fluctuations during the entire cycle.

The distal end of collapsible bladder exhibits rapid and wide range of fluctuations which can be explained by very strong fluid structure interactions happening due to sudden stoppage of flow. This is because the ' $U$ ' shaped tube is made of flexible plastic pipe and also the supporting structures are non rigid. An attempt has been made to graphically record the fluid velocity flow with help of doppler at the distal end of collapsible bladder but the flow in this region is very turbulent whereas other regions it is smooth.

\section{RESULTS}

Below are experiments conducted using above model which study the relationship rate of fluid flowing and the frequency of oscillations produced.

\subsection{About Collapsible Bladder}

The dimensions of the balloon in fully expanded state, which assumes a geometric shape of ellipsoid are: Horizontal diameter is $=11.5 \mathrm{~cm}$

Vertical diameter $=19 \mathrm{~cm}$

Volume of fully expanded Balloon is $=1600 \mathrm{cc}$

The thickness of the rubber used in the rubber is $=$ $0.75 \mathrm{~mm}$

\subsection{About Distal 'U' Shaped Tube}

The distal ' $U$ ' shaped tube is made of relatively flexible PVC pipe with following characteristics

The length of ' $U$ ' tube is $=60 \mathrm{~cm}$

Height of $\mathrm{U}$ tube is from collapsible balloon to distal rigid tube is $=30 \mathrm{~cm}$

Vertical height of distal rigid tube from flexible $\mathrm{U}$ shaped tube is $=140 \mathrm{~cm}$

Inner Diameter of $\mathrm{U}$ shaped flexible tube is $=12 \mathrm{~mm}$

Thickness of $U$ shaped tube is $=2 \mathrm{~mm}$

Inner Diameter of distal rigid tube is $=11 \mathrm{~m}$

Thickness of distal rigid tube is $=1.8 \mathrm{~mm}$

The angle of ' $U$ ' tube which makes to vertical is between $80^{\circ}-70$

Similar experiments were conducted in much small scale using small sized balloons and tubes which worked very well, though data was not recorded, due to low volume flows and small sized equipment used.

The dimensions of the pipes and bladder are so chosen to resemble those of small sized human beings cardiovascular system. The flows used are comparable to normal physiological range of blood flow. The oscillations produced by this experiment also are in range of normal heart beating frequency. The basic experiments illustrate how simple parameter of flow rate can be varied to alter the frequency of collapsing bladder (Tables 1 and 2). Also at constant flow conditions and when all other parameters are kept constant of varying height of the bladder from ground affects the frequency of collapsing bladder (Tables 3 and 4). Thus by altering these two simple parameters any desired flow condition can be simulated in laboratory. The effects of pipe's stiffness and diameters of tubing can be studied and their flow patterns analyzed when all other parameters are held constant. Also side branches can be attached to distal ' $U$ ' tube or rigid pipe which represent the branches of main vessels and their flow characteristics during pulsatile flow can be studied.

Here fall of pressures is sharp unlike the rise which is observed during pressure recordings inside large arteries and the pressures recorded here are in negative range which is reverse of that seen normally inside blood vessels. But the pressure fluctuations resemble closely to those recorded inside vascular compartment invasively. 
Table 1. Relationship of change in frequency of oscillations with change in flow rate when height of bladder from ground is constant.

\begin{tabular}{|c|c|c|c|c|c|c|}
\hline $\begin{array}{c}\text { Flow rate in } \\
\mathrm{ml} / \mathrm{sec}\end{array}$ & $\begin{array}{l}\text { Freq of collapse } \\
\text { per min }\end{array}$ & $\begin{array}{l}\text { Pressure at inlet } \\
\text { in } \mathrm{mm} \mathrm{Hg}\end{array}$ & $\begin{array}{l}\text { Max pressure at } \\
\text { outlet in } \mathrm{mm} \mathrm{Hg}\end{array}$ & $\begin{array}{l}\text { Min pressure at } \\
\text { outlet in } \mathrm{mm} \mathrm{Hg}\end{array}$ & $\begin{array}{c}\text { Range of } \\
\text { pressure } \\
\text { fluctuations in } \\
\mathrm{mm} \mathrm{Hg}\end{array}$ & $\begin{array}{c}\text { Average } \\
\text { velocity of flow } \\
\text { in } \mathrm{m} / \mathrm{sec}\end{array}$ \\
\hline 146 & 108 & -7 & -116 & -154 & 37 & 1.2 \\
\hline 200 & 100 & -9 & -122 & -158 & 37 & 1.8 \\
\hline 250 & 74 & -10 & -146 & -196 & 50 & 2.2 \\
\hline 278 & 80 & -7 & -94 & -150 & 56 & 2.5 \\
\hline 303 & 62 & -9 & -112 & -150 & 38 & 2.5 \\
\hline 332 & 52 & -7 & -100 & -127 & 26 & 2.6 \\
\hline 435 & 30 & -9 & -146 & -176 & 30 & 2.9 \\
\hline
\end{tabular}

Table 2. Similar experiment as above when the vertical height of ' $U$ ' tube from Ground is changed ( $h=90 \mathrm{~cm})$

\begin{tabular}{|c|c|c|c|c|c|c|}
\hline $\begin{array}{c}\text { Flow rate in } \\
\mathrm{ml} / \mathrm{sec}\end{array}$ & $\begin{array}{l}\text { Freq of collapse } \\
\text { per min }\end{array}$ & $\begin{array}{c}\text { Pressure at inlet in } \\
\mathrm{mm} \mathrm{Hg}\end{array}$ & $\begin{array}{l}\text { Max outlet pressure } \\
\text { in } \mathrm{mm} \mathrm{Hg}\end{array}$ & $\begin{array}{l}\text { Min outlet pressure } \\
\text { in } \mathrm{mm} \mathrm{Hg}\end{array}$ & $\begin{array}{l}\text { Range of pressure } \\
\text { fluctuations in } \mathrm{mm} \mathrm{Hg}\end{array}$ & $\begin{array}{l}\text { Average velocity of } \\
\text { flow in } \mathrm{m} / \mathrm{sec}\end{array}$ \\
\hline 85 & 128 & -5 & -50 & -70 & 20 & 0.75 \\
\hline 108 & 122. & -5.5 & -65 & -75 & 10 & 0.95 \\
\hline 187 & 86 & -6 & -59 & -70 & 11 & 1.6 \\
\hline 188 & 82 & -7 & -54 & -67 & 13 & 1.6 \\
\hline 218 & 75 & -5.5 & -60 & -67 & 7 & 1.9 \\
\hline 228 & 72 & -7 & -34 & -56 & 22 & 2.0 \\
\hline 250 & 70 . & -7 & -33 & -59 & 26 & 2.2 \\
\hline 286 & 72 & -4.5 & -63 & -79 & 6 & 2.5 \\
\hline 298 & 62 & 2.5 & -67 & -72 & 5 & 2.6 \\
\hline 342 & 45 & -5.5 & -60 & -75 & 15 & 3.0 \\
\hline 362 & 48 & -6 & -52 & -67 & 15 & 3.2 \\
\hline
\end{tabular}

Table 3. Variation of frequency with varying vertical height at constant flow rate of $=278 \mathrm{ml} / \mathrm{sec}$ average velocity of flow is 2.45 $\mathrm{m} / \mathrm{sec}$.

\begin{tabular}{cccccc}
\hline $\begin{array}{c}\text { Vertcial height from } \\
\text { ground in } \mathrm{cm}\end{array}$ & Freq of collapse per min & $\begin{array}{c}\text { Pressure at inlet in cm } \\
\text { of ater }\end{array}$ & $\begin{array}{c}\text { Outlet Max pressure in } \\
\mathrm{mm} \mathrm{Hg}\end{array}$ & $\begin{array}{c}\text { OutletMin pressure in } \\
\mathrm{mm} \mathrm{Hg}\end{array}$ & $\begin{array}{c}\text { Range of pressure } \\
\text { fluctuations in mm Hg }\end{array}$ \\
\hline 36 & 76 & -7 & -63 & -100 & 37 \\
96 & 66 & -8 & -68 & -108 & 40 \\
130 & 58 & -7 & -116 & -154 & 38 \\
142 & 70 & -7 & -94 & -130 & 37 \\
162 & 57 & -6 & -2 & -4 & 2 \\
\hline
\end{tabular}

\section{DISCUSSION}

In our study instead of classical models of 'starling resistor $[9,11]$ we use large balloon such that its diameter is greater than 3 times the inlet rigid tube diameter. Also the exit is not along the straight rigid tube but through the lower side of balloon such that when the balloon collapses the opposite wall impinges on the exit end completely occluding it and the flow stops (The path of fluid in the balloon is not straight as in 'starling resistor' but affectively changed to $90^{\prime}$ '). 
Table 4. Variation of frequency with change in height at constant flow rate of $240 \mathrm{ml} / \mathrm{sec} \&$ average velocity of flow is $2.14 \mathrm{~m} / \mathrm{sec}$.

\begin{tabular}{cccccc}
\hline $\begin{array}{c}\text { Vertical height from } \\
\text { ground in cm }\end{array}$ & $\begin{array}{c}\text { Frequency of col- } \\
\text { lapse per min }\end{array}$ & $\begin{array}{c}\text { Pressure at inlet in } \\
\mathrm{mm} \mathrm{Hg}\end{array}$ & $\begin{array}{c}\text { Max Pressure at } \\
\text { outlet in mm Hg }\end{array}$ & $\begin{array}{c}\text { Min pressure at outlet } \\
\text { in mm Hg }\end{array}$ & $\begin{array}{c}\text { Range of pressure } \\
\text { fluctuations in mm Hg }\end{array}$ \\
\hline 30 & 96 & -2 & -3 & -4 & 1 \\
50 & 92. & -4 & -1 & -21 & 20 \\
96 & 91 & -4 & -41 & -47 & -70 \\
130 & 86. & -5 & -60 & -96 & 30 \\
150 & 98 & -5 & -82 & -90 & 20 \\
165 & 58 & -4 & -80 & & 14 \\
\hline
\end{tabular}

There is another major deviation from classical approach the distal end is not exactly 'rigid straight tube' but a ' $U$ ' shaped flexible tube with mobile supports. The purpose of it was to make the distal end flexible, so that during the collapse, it executes rotational motion and also swings forward. The axial and radial motion of distal ' $U$ ' shaped pipe due fluid solid coupling can be described by series of differential equations [13]. As the supports holding the distal ' $U$ ' tube are elastic and the ' $U$ ' tube are itself flexible, due to strong fluid structure interactions occurring inside the system, the ' $U$ ' tube gets displaced [14] and the collapsed rubber bladder opens up and fills with liquid flowing continuously from reservoir above. Also some doubts about the flow resembling certain kinds of slug flow have to be dismissed totally as it is purely a monophasic flow and experimental observations revealed that the presence of air or any gas inside the tubes does not produce pulsatile flow. All the connections have to be airtight and very little air is sucked inside the tubes at the lower end of distal rigid tube (7 of Figure 2).

The basic mechanism is that once flow of water starts the positive hydrostatic pressure acting inside collapsible bladder proportional to height ho $\left(\mathrm{ho} \mathrm{d}^{*} \mathrm{~g}\right.$ ) becomes negative lateral pressure when flow is fully established flow and this negative pressure $\left(-\mathrm{h}_{1} * \mathrm{~d} * \mathrm{~g}\right)$ is proportional to height $h_{1}$ [17]. Also this negative pressure is the compressing transmural pressure acting on the collapsible bladder which causes it to buckle axisymmetrically at its distal end [12]. This sudden collapse occludes the mouth of ' $U$ ' shaped tube and stops the flow instantly creating a large -Ve waterhammer wave distally with strong junction coupling $[15,18]$.

The pressure wave form so produced can be analyzed by combined effects of pressure surges and pipe motion with help of method of characteristics and finite element methods respectively $[16,18]$. This strong junction coupling occurring at $U$ shaped tube has sufficient force to overcome the collapsing force of the bladder at the mouth of ' $\mathrm{U}$ ' tube $\left\{\left(\mathrm{h}_{1}-\mathrm{h}_{0}\right) * \mathrm{~d} \mathrm{~g}^{*} \mathrm{~A}\right\}$ and causes the

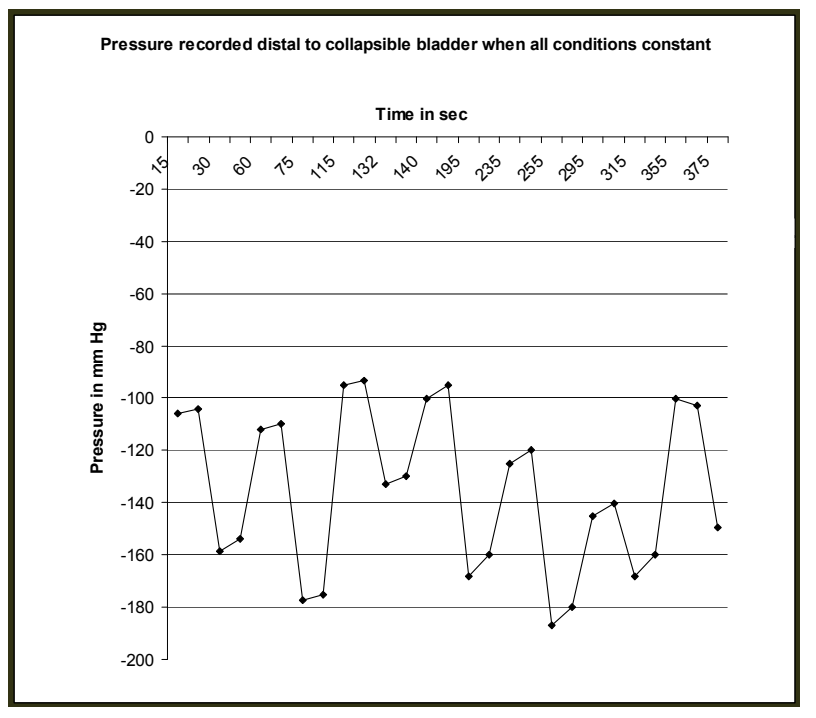

Typical pressure fluctuations recorded at the mouth of ' $U$ ' tube when all the flow conditions are held constant. Here flow rate was $=280$ $\mathrm{ml} / \mathrm{sec}$, vertical height of ' $U$ ' tube from ground is $140 \mathrm{~cm}$ and frequency of collapse is $=84 / \mathrm{min}$

Figure 4. Graph showing pressure readings with time.

bladder to open up with re-establishment of flow, thus producing pulsatile flow [18]. The total strain energy which has developed due to the fluid structure interactions can be calculated knowing bulk modulus of flowing liquid and elastic modulus of pipe as well as its mass density per unit length [17].

From these basic experiments it can be concluded that as the flow rate increases the frequency of oscillations progressively reduce and the average velocity of flow increases. The pressure at the inlet of balloon remains relatively constant with minor fluctuations per collapse of bladder. The outlet pressure fluctuates widely and the range is $30-40 \mathrm{~mm} \mathrm{Hg}$ which can be comparable to pulse pressure of human cardiovascular system.

Definite relationship between pressure and flow rate could not be established one reason being relatively insensitive instruments used to record a very dynamic and 
unstable pressure tracing. The minimum flow where it functions is where the flow inside the pipe work becomes closed channel laminar flow [17].

That means the whole of pipe area is in contact with flowing water. At flow rates below this it is open channel flow. Also the velocity of flow is $0.5-2 \mathrm{~m} / \mathrm{sec}$ which is very low. At flow velocity $>3 \mathrm{~m} / \mathrm{sec}$ or at higher Reynolds numbers the efficiency markedly falls and little higher flow velocity it doesn't behave as pulsatile balloon but it simply expands and remains in that position and water starts flowing passively. When diameter of $U$ and distal pipe is increased the lower and upper flow rate limit where these pulsations are observed both are increased and also simultaneously the range at which operates efficiently are increased correspondingly.

Yannick et al. performed in a specially designed mockup simulating the heart's behavior (the Dual Activation Simulator) to understand pulsatile flow inside heart like chambers in terms of mechanical behavior to understand cardiovascular diseases in laboratory without resorting to animal models or patients [19].

The gear pumps used by Issartier et al., Petersen et al., etc produce cavitation and damage to suspended particles [4-5] whereas the present model the occurrence of cavitation is very less and can be easily prevented by altering flow conditions. There is also no damage to blood particles as it does not involve rotating metal gears.

Peristaltic pumps which were developed later to prevent particle damage of gear pumps suffer the drawback of production of only limited subset of waveforms even if they are computer controlled and the systems lack flexibility to operate under wide flow conditions $[4,6,7]$. Also generating continuous flow from peristaltic pumps is difficult. The present model operates under wide range of flow conditions which can be produced by simply opening the inflow valve or raising the height of collapsible bladder from ground. Besides pulsatile flow, continuous can be easily produced simply by halting the oscillations of ' $U$ ' shaped tube and no further additional arrangement is required.

Microcomputer controlled piston pumps are very complicated, difficult to set up and cumbersome to operate [4-7]. The present apparatus offers an easier solution of producing pulsatile flow in laboratory by using readily available cost effective materials and can save lot of expenses and power.

The collapse of collapsible bladder resembles somewhat superficially of "beating heart" and waveforms produced are very close to invivo flow including sudden surges of pressures seen during valve closure. The pulsatile flow so produced can be studied for progression of diseases like atherosclerosis, effects of vessel wall stiff- ness and other properties for development of vascular diseases like hypertension and atherosclerosis.

Initial preliminary studies the apparatus works even when glycerol water having viscosity similar to blood are used as flowing liquid instead of water. However this is a pilot study and needs to be validated by further research and all the variables which affect the flow have to be studied more exhaustively with better instrumentation and advanced mathematical approach, before real useful conclusions drawn.

\section{CONCLUSIONS}

A novel and cost-effective pulsatile flow generator can be constructed using a large collapsible bladder connected to a flexible ' $U$ ' shaped tubing system and the pulsatile flow so produced can be used as simulation model for studying in vivo blood flow.

\section{AUTHOR'S CONTRIBUTIONS}

PUP developed the experimental setup from beginning, conducted the experiments and drafted the manuscript. NBS provided technical support for conducting experiments in MSRIT lab and suggested the utility of using it as simulation model for cardiovascular system.

\section{ACKNOWLEDGEMENTS}

I thank MSRIT institute for providing me laboratory support for my research especially Dept of Civil engineering and the Principal of MSRIT.

\section{REFERENCES}

[1] Afshin, A.-B., Mohammad, T.-S., Nasser, F., et al. (2008) A new system to analyze pulsatile flow characteristics in elastic tubes for hemodynamic applications. American Journal of Applied Sciences, 5(12), 1730-1736.

[2] Chatzizisis, Y.S. and Giannoglou, G.D. (2006) Pulsatile flow: A critical modulator of the natural history of atherosclerosis. Electronic Publication, 67(2), 338-340.

[3] Finol, E.A. and Amon, C.H. (2001) Blood flow in abdominal aortic aneurysms: Pulsatile flow hemodynamics. Journal of Biomechanical Engineering, 123(5), 474-484.

[4] Law, Y.F., Cobbold, R.S.C., et al. (1987) Computer-controlled pulsatile pump system for physiological flow simulation. Medical \& Biological Engineering \& Computing, 25(5), 590-595.

[5] Petersen, J.N. (1984) Digitally controlled system for reproducing blood flow waveforms in vitro. Medical and Biological Engineering and Computing, 22(3), 277-280.

[6] Eriksson, A., Persson, H.W. and Lindstrom, K. (2000) A computer-controlled arbitrary flow wave form generator for physiological studies. Review of Scientific Instruments, 71(1), 235-242.

[7] Holdswoth, D.W., Rickey, D.W., et al. (1991) "Computer-controlled positive pump for physiological flow 
simulation," Medical \& Biological Engineering \& Computing, 29(4), 565-570.

[8] Kamm, R.D. and Shapiro, A.H. (1979) Unsteady flow in a collapsible tube subjected to external pressure or body forces, Journal of Fluid Mechanics, 95(1), 1-78.

[9] Heil, M. and Jensen, O.E. (2003) Flows in deformable tubes and channels -- Theoretical models and biological applications. Chapter 2 of: flow in collapsible tubes and past other highly compliant boundaries. Pedley, T.J. and Carpenter, P.W., Eds., Kluwer, Dordrecht, Netherlands Heil, 15-50.

[10] Heil, M. (1996) The stability of cylindrical shells conveying viscous flow. Journal of Fluids and Structures, 10(2), 173-196.

[11] Heil, M. and Pedley, T.J. (1996) Large post-buckling deformations of cylindrical shells conveying viscous flow. Journal of Fluids and Structures, 10(6), 565-599.

[12] Heil, M. (1998) Stokes flow in an elastic tube -- A largedisplacement fluid-structure interaction problem. The International Journal for Numerical Methods in Fluids, 28(2), 243-265.

[13] Tijsseling, A. (2007) Water hammer with fluid-structure interaction in thick-walled pipes. Computers and Structures, 85(11-14), 844-851.

[14] Heinsbroek, A.G.T.J. and Tijsseling, A.S. (1994) The influence of support rigidity on waterhammer pressures and pipe stresses. Proceedings of the Second Interna- tional Conference on Water Pipeline System and BHR Group, Edinburgh, 17-30.

[15] Wiggert, D.C. and Tijsseling, A. S. (2001) Fluid transients and fluid-structure interaction in flexible liquid filled piping. ASME, 455-481.

[16] Tijsseling, A.S. and Heinsbroek. A.G.T.J. (1999) The influence of bend motion on waterhammer pressures and pipe stresses. Proceedings of the 3rd ASME \& JSME Joint Fluids Engineering Conference, Symposium S-290 Water Hammer (Editor JCP Liou), San Francisco, July 1999, ASME-FED, 248, Paper FEDSM99-6907.

[17] Kumar, D.S. (2010) Fluid mechanics and fluid power engineering. S. K. Kataria \& Sons Publishers and Distributors, New Delhi, Chapter 9.

[18] Ahmad A. and Ali R.K. (2008) Investigation of the junction coupling due to various types of the discrete points in a piping system. The 12th International Conference of International Association for Computer Methods and Advances in Geomechanics (IACMAG), Goa, India.

[19] Knapp, Y., Bertrand, E. and Mouret, F. (2003) 2D-PIV measurements of the pulsatile flow in a left heart simulator. Proceedings of PSFVIP-4, Chamonix, F4082.

[20] Wang, W.X. and Christopher D.B. (2007) Effects of collapsible-tube-induced pulsation vigour on membrane filtration performance. Journal of Membrane Science, $\mathbf{2 8 8}$ (1-2), 298-306. 